
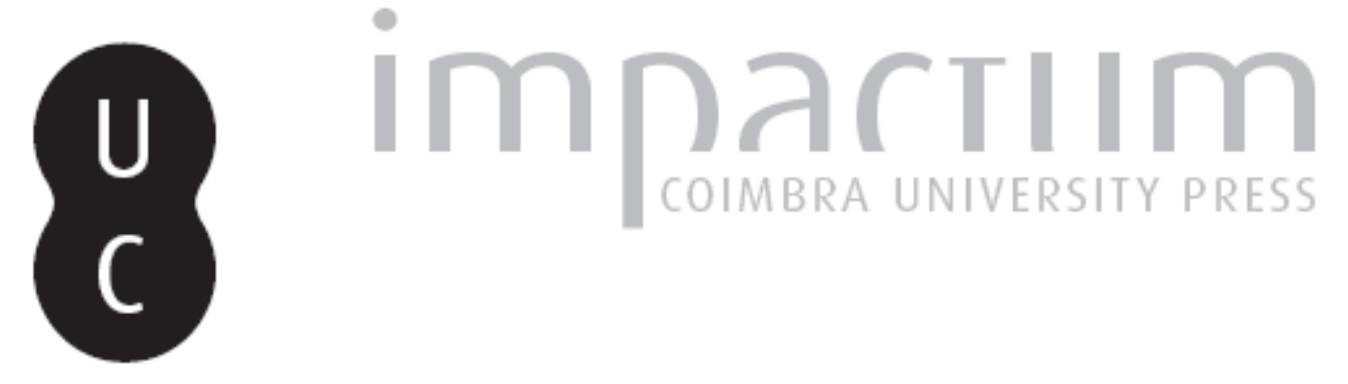

Pode a ontologia heideggeriana servir de índice de finitude para o divino?

Autor(es): $\quad$ Toledo, Daniel da Silva

Publicado por: $\begin{aligned} & \text { Universidade Católica de Petrópolis; Instituto Brasileiro de Informação } \\ & \text { em Ciência e Tecnologia }\end{aligned}$

URL

persistente:

URI:http://hdl.handle.net/10316.2/33036

DOI:

DOI:http://dx.doi.org/10.14195/1984-6754_3-2_2

Accessed : $\quad$ 26-Apr-2023 15:58:36

A navegação consulta e descarregamento dos títulos inseridos nas Bibliotecas Digitais UC Digitalis, UC Pombalina e UC Impactum, pressupõem a aceitação plena e sem reservas dos Termos e Condições de Uso destas Bibliotecas Digitais, disponíveis em https://digitalis.uc.pt/pt-pt/termos.

Conforme exposto nos referidos Termos e Condições de Uso, o descarregamento de títulos de acesso restrito requer uma licença válida de autorização devendo o utilizador aceder ao(s) documento(s) a partir de um endereço de IP da instituição detentora da supramencionada licença.

Ao utilizador é apenas permitido o descarregamento para uso pessoal, pelo que o emprego do(s) título(s) descarregado(s) para outro fim, designadamente comercial, carece de autorização do respetivo autor ou editor da obra.

Na medida em que todas as obras da UC Digitalis se encontram protegidas pelo Código do Direito de Autor e Direitos Conexos e demais legislação aplicável, toda a cópia, parcial ou total, deste documento, nos casos em que é legalmente admitida, deverá conter ou fazer-se acompanhar por este aviso.

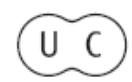



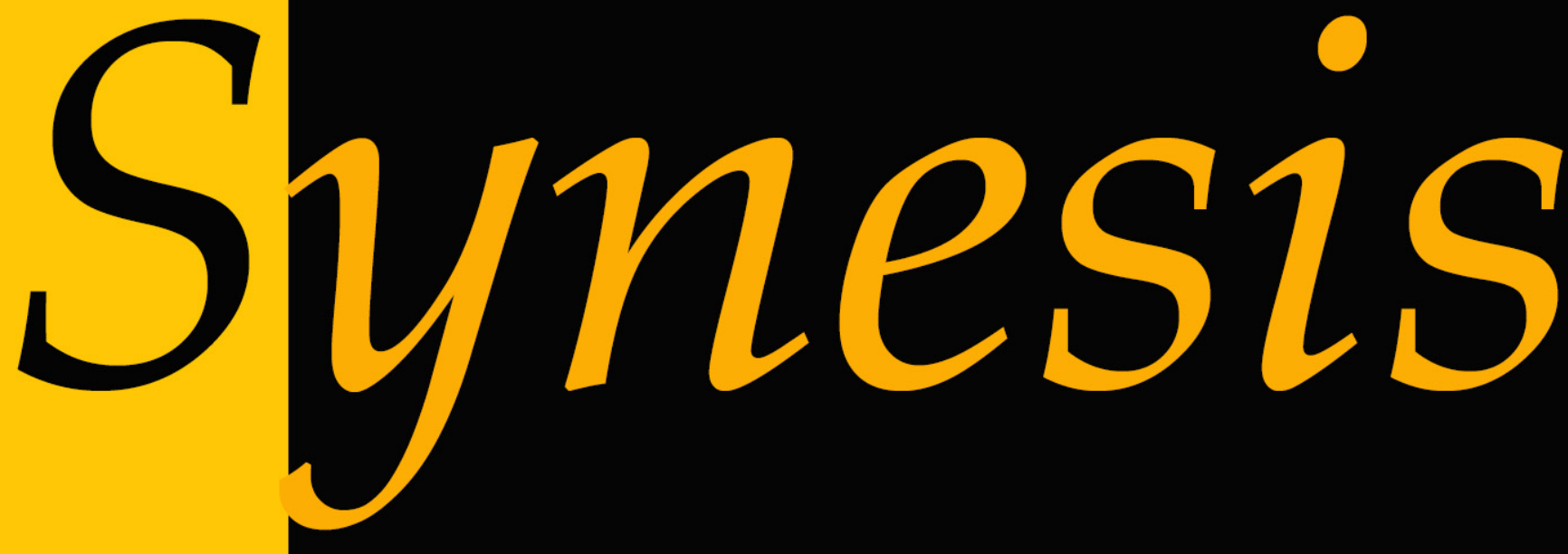

Revista do Centro de Teologia e Humanidades ISSN 1984-6754

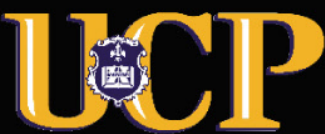




\title{
PODE A ONTOLOGIA HEIDEGGERIANA SERVIR DE ÍNDICE DE FINITUDE PARA O DIVINO? ${ }^{1}$
}

\author{
Daniel da Silva Toledo \\ Em que medida padece o deus \\ que se envia enquanto raio \\ no lampejo sagrado? \\ HEIDEGGER
}

\begin{abstract}
Resumo: Nossa proposta repousa basicamente na tentativa de indicar uma determinada relação de compreensão entre o mortal e a divindade a partir da inserção dessa relaçáo no horizonte da ontologia de Martin Heidegger. Tentaremos com isso indicar um meio de compreensão através do qual o ser finito que nós mesmos somos possa pensar a divindade a partir desse nosso próprio caráter de finitude. Inserindo a divindade no mesmo horizonte de compreensão histórico-temporal do ser-no-mundo que é sempre ser-para-a-morte, buscaremos apontar uma determinada maneira de pensar os deuses em sua essencial possibilidade de ausência. Divinos e mortais serâo colocados em jogo a partir da dinâmica de recusa essencialmente constitutiva do ser. Com essa tentativa de mostrar em que medida a concepçáo heideggeriana do divino, que em sua essência fugidia se recolhe na dimensão de velamento do ser, é devedora do horizonte de finitude de nosso ser-no-mundo, acreditamos, por fim, poder contribuir também para um maior estreitamento do vínculo de sentido entre o evento da morte de Deus e a precariedade do mortal reportado ao abismo do ser e direcionado para a proposta de superaçáo da metafísica.
\end{abstract}

Palavras-chaves: Heidegger; Deus; finitude.

Abstract: Our proposal rests basically on the attempt to indicate a certain relation of comprehension between the mortal and the divinity from the insertion of such relation on the horizon of Martin Heidegger's ontology. As such, we attempt to indicate a means of comprehension through which the finite being which we are ourselves may think about divinity in the same horizon of historic-temporal comprehension of the being-in-the-world which is always a being-for-death, we aim to point out a certain way of thinking about gods in their essential possibility of absence. Divines and mortals will be put at stake from the dynamic denial essentially constituting the being. With such attempt of showing on which grounds the Heideggerian concept of the divine, in its escaping essence refuses itself in the dimension of hiding the being, is also indebted to the horizon of our being-in-the-world, we believe, therefore, to be able to contribute also to a greater strengthening of the bond of meaning between the event of the death of God and the precariousness of the mortal reported to the abyss of the being and directed to the proposal of overcoming of metaphysics.

Key words: Heidegger; God; finiteness.

\footnotetext{
${ }^{1}$ Artigo recebido em 13/10/2011 e aprovado para publicação pelo Conselho Editorial em 02/12/2011.

2 Doutorando em Ciência da Religião pela Universidade Federal de Juiz de Fora (UFJF). Currículo Lattes: http://lattes.cnpq.br/9091013835362460 . Email: dasilvatoledo@yahoo.com.br.
} 


\section{Introduçáo}

$\mathrm{Na}$ Brief über den Humanismus, ao fazer alusão ao horizonte de sentido instituído através de Sein und Zeit, Heidegger admite que "com a determinação existencial do homem, nada ainda está decidido sobre o 'ser-aí do deus' [Dasein Gottes] ou seu 'não-ser', como tampouco sobre a possibilidade ou a impossibilidade dos deuses". ${ }^{3}$ Contudo, de imediato ele procura deixar claro não se tratar de um "indiferentismo" (Indifferentismus). ${ }^{4}$ Isto porque, apesar dele de fato não poder oferecer uma determinação última quanto a essa questáo, ele já não podia mais deixar de considerá-la, uma vez que, desde 1929, isto é, logo após a publicação de sua principal obra, decorrera, em uma nota do texto Vom Wesen des Grundes, a necessidade de uma abertura para a possibilidade de que, "através da clarificação da transcendência, seja conquistado, antes de tudo, um conceito mais satisfatório do Dasein como aquele ente em referência ao qual pode ser questionado como ele está ontologicamente marcado pela relação com o deus". ${ }^{5}$

Entretanto, se a partir da instituição da Geviert os celestes só podem ser pensados já sempre inseridos na relação com o mortal, ${ }^{6}$ e se este, por sua vez, só pode ser compreendido a partir de seu horizonte temporal, como poderíamos então perguntar pela essência da deidade condicionada a este horizonte de finitude? Logo, a questáo que se faz central aqui é em que medida esta relação pode repousar sobre a problemática da finitude, uma vez que "a finitude do homem, para Heidegger, só é considerada horizonte ontológico"?7

\footnotetext{
${ }^{3}$ HEIDEGGER: Wegmarken, p. 350.

${ }^{4}$ HEIDEGGER: Wegmarken, p. 351.

${ }^{5}$ HEIDEGGER: Wegmarken, p. 159. Daí essa mesma citação ser retomada na Brief über den Humanismus! Cf.: HEIDEGGER: Wegmarken, p. 351.

6 "Pensar um deus que fale por si é absolutamente sem sentido". HEIDEGGER: Die Grundbegriffe der Metaphysik, p. 346. "Sendo assim, é impossível que um deus 'fale' ('palavra' de deus)". HEIDEGGER: Sein und Wahrheit, p. 101. Por outro lado, "homem algum inventou por si a linguagem, ou seja, homem algum foi suficientemente forte para romper com a violência do silêncio, a não ser sob a coação do deus". HEIDEGGER: Hölderlins Hymnen “Germanien” und "Der Rhein”, p. 218.

${ }^{7}$ STEIN: Compreensáo e Finitude, p. 291.
} 


\section{A diferença essencial entre o ser e a divindade}

Quanto à referida restrição, Heidegger foi, de fato, categórico ao afirmar que “ontologia é o índice da finitude. Deus não a tem". ${ }^{8}$ Contudo, o Deus que de forma alguma pode dispor da finitude, isto é, o Deus da infinitude, é o Deus da teologia. Todavia, é bem sabido que "é um fato: isso não é a última palavra de Heidegger acerca de Deus e do divino. Muito pelo contrário". ${ }^{9}$ A partir disso, e para que náo andemos em círculo, devemos tentar avançar com a questáo na procura de uma concepçáo do divino que possa ser inserida no horizonte da compreensão ontológica resguardada do risco de reincidência no plano da constituição onto-teo-lógica da metafísica.

Sabemos que, em termos gerais e de maneira preponderante, Heidegger entende por "Deus da metafísica" o Deus que sofre a imiscuição onto-teo-lógica. Como primeira demarcação disso, temos o fato de que o Deus metafísico não respeitaria um critério fundamental instituído pelo pensamento de Heidegger: a diferença ontológica. Como essa diferença deve ser traduzida basicamente como a diferença entre o ente e aquilo que ele não é, ou seja, o ser, poderíamos dizer que o problema repousa substancialmente no fato de que o Deus da metafísica, enquanto absoluto, absorve o ser. Justamente nisso persiste a maior dificuldade, uma vez que, pelo fato da metafísica ser "teológica” neste sentido, isto é, no sentido que "deriva todo ser do ente do ente supremo enquanto causa primeira", que ela nunca se permite "sequer colocar uma decisão sobre o Deus" ${ }^{10} \mathrm{O}$ que acontece, por conseguinte, é que o horizonte metafísico encobre a possibilidade que a divindade seja compreendida para além das linhas de forças que balizam esse horizonte no qual ela acaba sendo encerrada pela tradição. Diante disso, o que parece justificar ainda mais essa posição de Heidegger repousa no fato de que "a mais íntima inessência do cristianismo (enquanto metafísica e a título de cultura) consiste no fato de que ele náo pode admitir uma rejeição de Deus por parte do ser”. ${ }^{11}$

\footnotetext{
${ }^{8}$ Heidegger, apud STEIN: Compreensão e Finitude, p. 291.

${ }^{9}$ DUBOIS: Heidegger, p. 214.

${ }^{10}$ HEIDEGGER: Metaphysik und Nihilismus, p. 92.

${ }^{11}$ HEIDEGGER: Über den Anfang, p. 132.
} 
É em virtude deste condicionamento que Heidegger, sempre diante de tal problema, afirmou de maneira categórica que ele jamais tentaria pensar a essência de Deus por meio do ser. A conseqüência mais importante disso repousou entâo na seguinte interdição legada: "De Deus não se pode predicar nem a finitude e nem a infinitude, nem que é nem que não é". ${ }^{12}$

Não obstante, como já indicado, a experiência de deus só é possível para Heidegger inserida no horizonte de compreensão do ser-no-mundo que é sempre já ser-para-a-morte. Daí, inclusive, a afirmação de que "o próprio deus é 'tempo". ${ }^{13}$ Frente a isso, devemos reconhecer que Heidegger nunca pôde deixar de assumir que também a experiência essencial de Deus e sua manifestaçáo (na medida em que ela vem ao encontro do homem) se dão sempre a partir da abertura fáctico-temporal do ser, ${ }^{14}$ o que não significa jamais que o ser possa valer como predicado possível de Deus. Com isso, entendemos que o fato do principal problema da metafísica repousar na imiscuição onto-teo-lógica não deve significar que deva ser vedada qualquer possibilidade de relaçáo entre o ser e a divindade. ${ }^{15}$ Até mesmo porque que "os deuses escapem, não significa que eles tenham desaparecido do Dasein do homem". ${ }^{16}$ Frente a toda essa dificuldade, parece-nos que o caminho a ser seguido conduz à necessidade de desdobrar a questão "se nós, enquanto homens, isto é, enquanto em nossa essência 'eksistente', devemos poder realizar a experiência de uma relação do deus com o homem” no sentido de "poder questionar rigorosamente se o deus se aproxima ou se retira". ${ }^{17}$

Uma vez respeitada essa delimitação, deve estar claro que a tarefa conseqüente só pode partir da possibilidade de repensar a divindade justamente em uma radical relaçáo de

${ }^{12}$ Azevedo, apud STEIN: Compreensão e Finitude, p. 291.

${ }^{13}$ HEIDEGGER: Hölderlins Hymnen "Germanien” und "Der Rhein”, p. 54. "Uma condição necessária para isso é que se torne tempo para que 'o divino nos atinja”. HEIDEGGER: Hölderlins Hymnen "Germanien” und "Der Rhein", p. 58.

14 "Os deuses devem ser deuses e os homens devem ser homens de tal forma que nunca podem ser um sem o outro". HEIDEGGER: Erläuterungen zu Hölderlins Dichtung, p. 69. "Quem seria o homem vem à luz segundo a palavra de Heráclito somente no pólemos, no conflito entre deuses e homens, na ocorrência da irrupção do próprio ser". HEIDEGGER: Einführung in die Metaphysik, p. 107. "Repare-se que a questão a propor não é, como na formulação tradicional, a existência de Deus, mas a relação do Dasein com Deus". NUNES: Crivo de papel, p. 31. "Sabe-se, porém, qual o seu lugar de adveniência: o Da do Dasein, o fáctico da existência, que é onde o homem se confronta a deus." NUNES: Crivo de papel, p. 42.

${ }^{15}$ Heidegger foi bem categórico quanto a isso ao afirmar que "a deidade do deus se origina da manifestação essencial do ser" (HEIDEGGER: Besinnung, p. 240) e que "fora do ser não há mais possibilidade alguma para os deuses", mas apenas "desdivinização". HEIDEGGER: Besinnung, p. 244.

${ }^{16}$ HEIDEGGER: Hölderlins Hymnen “Germanien” und "Der Rhein”, p. 95.

${ }^{17}$ HEIDEGGER: Wegmarken, p. 351. 
negação com o ser. Segundo bem compreendeu Benedito Nunes, neste caso, "um outro deus é reclamado pela finitude". ${ }^{18}$ Esse "outro" colocado em relação com a finitude não pode mais ser compreendido como o imortal absoluto, mas deve agora ser entendido no sentido de já não mais presente. A partir dessa profunda relaçáo de recusa com o que é presente, o "último deus" (der letzte Gott), por exemplo, após a morte de Deus, “desvela a mais íntima finitude do ser". ${ }^{19}$ Trata-se de realizar a experiência de uma precariedade comum.

Quanto a isso, porém, pode parecer que Heidegger institui uma clivagem de perspectivas na medida em que essa relação de negação aparentemente dupla implicaria uma espécie de "passagem" pensada enquanto superação de uma relação de exclusão para uma relação de afirmação, ainda que a partir da diferença. Diante disso, o que tentaremos aqui será buscar apontar para a necessidade de uma restituição da circularidade possível entre o caráter de finitude do mortal e o caráter de afastamento ou retraçáo do divino de uma tal forma que possibilite uma experiência que preserve a relaçáo de diferenciaçáo do divino acerca do ser em sua totalidade.

\section{A morte enquanto horizonte de compreensáo da relaçáo entre deuses e mortais}

No seminário invernal compreendido entre os anos de 1966 e 1967, na Universidade de Freiburg, Heidegger e Eugen Fink, conjuntamente, ministram um curso em forma de debate acerca dos fragmentos de Heráclito. Por ocasião da aula dedicada à "relação entre homens e deuses", no momento do colóquio em que procuravam entender o que o "todo" heráclitico abarcava, ou seja, o que podia ser referendado ao ente em sua totalidade, Heidegger interpela: "entes são também os deuses", ao passo que Fink replica: "mas com isso você já designa entes que não são fenomenais [unphänomenal]". ${ }^{20}$ Isto em virtude do fato de, segundo Fink, serem entes que não podem ser demonstrados. ${ }^{21}$ Não obstante, caso devamos aceitar que

${ }^{18}$ NUNES: Crivo de papel, p. 42.

${ }^{19}$ HEIDEGGER: Beiträge zur Philosophie, p. 410. Por isso é que "o homem aprende a conhecer melhor que este deus é o 'último' quando ele próprio suporta o termo extremo e último da morte”. BRITO: Heidegger et l'hymne du sacré, p. 148.

${ }^{20}$ HEIDEGGER/FINK: Heraklit, p. 143.

${ }^{21}$ Cf. HEIDEGGER/FINK: Heraklit, p. 144. 
os deuses possam se manifestar sem, contudo, se mostrarem como tais, isso abre para que, segundo reconhece o próprio Fink, "haja possibilidades de aparência de coisas que se mostrem diferentes do que elas são, sem que essa aparência deva ser vista a partir da ilusão subjetiva". ${ }^{22}$

Essa importante colocação dá ensejo para que, neste mesmo seminário, Heidegger entre também no debate da questão sobre a morte, mas agora não somente em relação à finitude dos mortais, como também em confrontação com a deidade.

Interessante notar que Fink refere-se aos deuses quase sempre como imortais, referência diante da qual Heidegger parece apresentar reservas, continuando a preferir chamálos de deidades. ${ }^{23}$ Mas por mais que Fink tenha-os como imortais, ele, por fim, acaba tendo de se aproximar de Heidegger ao aceitar a relação dos deuses com a morte a partir da perspectiva de um contraste náo necessariamente excludente, no sentido de que estes, a partir de sua relaçáo essencial com os mortais, estáo sujeitos à experiência da morte que não é de toda experiência alheia, mas uma experiência comum a partir de uma tensão que determina a própria relação entre eles. Diante disto, Fink questiona de maneira intrigante: "os deuses vivem a morte dos homens mortais. Significa isto que a vida dos deuses é a morte dos homens? E por outro lado: morrem os homens a vida dos deuses?" 24

Como essa relação, de certa forma, coloca os deuses numa significativa referência à morte, também interessa a Heidegger saber se o fragmento 88 de Heráclito, que reza o jogo entre vida e morte, pode ser reportado tanto aos homens quanto aos deuses. ${ }^{25}$ Essa questáo aparece como importante em virtude do fato de que para Heidegger a condiçáo de finitude do humano já havia se mostrado como originariamente determinada pela relação entre mortais e divinos: "os mortais são os homens. Eles se chamam os mortais porque eles podem morrer. Morrer significa ser capaz da morte como morte. Somente o homem morre, e isso de maneira

\footnotetext{
${ }^{22}$ HEIDEGGER/FINK: Heraklit, p. 144.

${ }^{23}$ Fink ainda concebe um "ser imutável dos deuses" (Das unwandelbare Sein der Götter). HEIDEGGER/FINK: Heraklit, p. 164. Não obstante sua reserva apresentada neste momento, Heidegger em outra ocasião acolhe de Hölderlin o termo "imortalidade" (Unsterblichkeit) para se referir à "divindade" (Göttlichkeit). HEIDEGGER: Erläuterungen zu Hölderlins Dichtung, pp. 168, 169. Além disso, curiosamente, na conferência "Para que poetas?”, ele também fala do "mortal" como aquele que "se coloca a caminho do outro lado da vida"! HEIDEGGER: Holzwege, p. 300.

${ }^{24}$ HEIDEGGER/FINK: Heraklit, p. 163.

${ }^{25}$ Cf. HEIDEGGER/FINK: Heraklit, p. 193.
} 
constante, na medida em que ele permanece sobre a terra, sob o céu, diante dos divinos". ${ }^{26}$ É assim, ou seja, a partir deste espelhamento, que na copertença da Geviert, divinos e mortais se "abrem no enigma de sua essência". ${ }^{27}$

Diante do questionamento de Heidegger, Fink tenta responder à sua própria colocação da seguinte maneira: "os deuses não estão livres da morte [todlos] no sentido de uma privaçáo, eles náo são intocáveis pelo destino da morte, mas eles estáo voltados para a morte dos mortais através da referência à morte, da qual eles, de certa forma, estão livres” ${ }^{28}$ A dúvida de imediato decorrente, apesar de óbvia, é impositiva: ora, como poderiam os deuses estarem voltados para a morte estando livres da mesma?

Os deuses não se anulam, ao contrário de cada Dasein que encontra seu fim na morte. Logo, a morte do deus diz respeito à experiência da possibilidade de ausência de algo outro. Com isso, Eugen Fink consegue perceber tratar-se de um determinado jogo, de uma espécie de "tomar parte" 29 na dinâmica entre dar-se e ausentar-se.

Os deuses de forma alguma são entidades neutras, uma vez que também eles se manifestam no tempo. ${ }^{30}$ Partilhando do mesmo horizonte temporal de sentido, a compreensão que nosso ser-no-mundo possui dos deuses depende essencialmente da forma como encaramos nossa própria finitude. Neste sentido, a divindade sempre esteve, de certa forma, condicionada ao caráter de finitude do mortal. Esta finitude só pode ser compreendida a partir da perspectiva do declínio, do sucumbir em seu caráter de transcendência, que constitui aqui a exposição à abertura abissal do divino. Quanto a isso, devemos também concordar com Fink acerca da tese de que a totalidade do divino deve ser concebida a partir de uma relação essencial com o caráter de "declínio" do mortal. ${ }^{31}$ Diante desta interpretação, Heidegger não pôde deixar de admitir a seguinte problemática:

A questáo para mim é em que medida podemos saber algo puramente original sobre os deuses em suas relaçôes com o homem [...]. Grosso modo se poderia dizer em referência à vossa interpretaçáo que o senhor imputa aos

\footnotetext{
${ }^{26}$ HEIDEGGER: Vorträge und Aufsätze, p. 144.

${ }^{27}$ HEIDEGGER: Vorträge und Aufsätze, p. 173.

${ }^{28}$ HEIDEGGER/FINK: Heraklit, p. 151.

${ }^{29}$ Cf. HEIDEGGER/FINK: Heraklit, p. 151.

30 "Para Heidegger, com efeito, o deus não pode ser pensado como aquilo que é sem tempo nem história". BRITO: Les dieux et le divin d'après Heidegger, p. 80.

${ }^{31}$ HEIDEGGER/FINK: Heraklit, p. 168.
} 
deuses uma ontologia existencial. Neste sentido, vossa interpretaçáo vai em direção de uma ontologia existencial não somente do homem em relação aos deuses, mas também ao contrário, dos deuses em sua relação com os homens. ${ }^{32}$

Em resposta, Fink é perspicaz: "deuses e homens não figuram duas esferas separadas. Cabe ver não o corismós, mas a imbricação da auto-compreensão e da compreensão do ser de divinos e mortais" ${ }^{33}$ De fato, se para uma compreensão mais ampla do mortal enquanto serno-mundo é fundamental sua relaçáo com o divino, como atesta todo o pensamento de Heidegger após a Kehre, então se deve não somente assumir o desafio de se pensar uma ontologia existencial que pressuponha sempre já um determinado sentido para o divino, como antes também assumir que essa pressuposição iniludível acarreta, de maneira não menos inevitável, uma certa proporcionalidade antropológica do divino. ${ }^{34}$ Proporcionalidade que não pode deixar de se pautar pelo horizonte da finitude, náo em um sentido de suplantaçáo, mas antes de assunção da precariedade diante do abismo do ser, da abertura de mundo em seu sentido mais amplo. Assim, a morte de Deus radicaliza ainda mais a precariedade do mortal na medida em que o expóe à experiência do infundado, ao abismo do ser. A experiência dessa precariedade constitui a própria essência do mortal. ${ }^{35}$ Dessa nova compreensão resulta uma importante admissão de Heidegger:

Vai daí de não se falar de uma maneira grosseira em deuses e homens como diferentes seres vivos, dos quais uns seriam imortais e outros mortais. $\mathrm{Na}$ terminologia de Sein und Zeit a imortalidade não seria uma categoria, mas um existencial, um modo como os deuses se relacionam com seu ser. ${ }^{36}$

Apesar de ser intrigante essa admissáo pontual da imortalidade como possível elemento existencial, o ganho mais significativo deste postulado conjunto repousa na possibilidade de se estipular que desde a origem dessa relação a mesma "não pode ser descrita

\footnotetext{
${ }^{32}$ HEIDEGGER/FINK: Heraklit, p. 179.

${ }^{33}$ HEIDEGGER/FINK: Heraklit, p. 180.

${ }^{34}$ Para que se possa distinguir "que tal relação não é mera representação do homem" (HEIDEGGER/FINK: Heraklit, p. 202), essa "proporcionalidade antropológica do divino" deve se colocar em tensão com a representaçáo dos deuses sob os traços dos homens, dada que esta última tende mais facilmente a incorrer em uma redução violentadora!

${ }^{35}$ Cf. HEIDEGGER: Holzwege, pp. 267, 270.

${ }^{36}$ HEIDEGGER/FINK: Heraklit, p. 180.
} 
de fora", mas tão somente a partir de "referências internas" à própria existência em seu caráter ontológico. ${ }^{37}$

Essa apropriação ontológica da relação com o divino permitiu a Heidegger neste momento inferir que "o homem é a condição existencial dos deuses". ${ }^{38}$ Entendemos que o resultado dessa discussáo apresentada pode possibilitar um avanço significativo do projeto heideggeriano de superação da metafísica, pois, contra qualquer risco de reincidência em um subjetivismo a-teológico, essa ousada e inovadora perspectiva (apresentada, até onde sabemos, somente neste referido seminário!) traz a questáo do divino das alturas metafísicas para o solo existencial sem deixar de se preservar quanto ao risco da imanentizaçáo, dado que a partir dela os mortais devem se colocar em relaçáo com o divino justamente a partir de sua precariedade, ou seja, a partir de sua impossibilidade de determinar os sentidos de mundo que lhe excedem por estarem lançados no abismo do ser. Daí concluir Heidegger que "por isso é que a relação entre homens e deuses é algo elevado e complicado, que náo pode ser determinado pela terminologia corrente da teologia metafísica". ${ }^{39}$

Náo estamos querendo dizer com tudo isso que deuses e homens se relacionariam com a morte de uma mesma maneira, nem tampouco que os deuses estariam sujeitos à morte mal compreendida como aniquilação ou anulação do ser, mas simplesmente que a compreensão originária da relação entre eles depende de tal questáo. Essa compreensão deve repousar no fato de que, ao ter de se relacionar com a divindade condicionado sempre por sua própria finitude, o mortal, diante do recuo dos deuses, isto é, diante do lhe excede, se expóe à própria precariedade do entendimento que ele pode ter dos mesmos e, conseqüentemente, de si próprio. É neste horizonte de tensão que se dá “a copertença do deus e do homem” (das Zusammengehören des Gottes und des Menschen). ${ }^{40} \mathrm{Na}$ medida em que essa inconsistência atinge a modalidade essencial da epifania, isto é, do dar-se pela ausência, também os demais sentidos de mundo sustentados pelos deuses são sempre passíveis de se colocar em suspensão.

\section{Consideraçóes finais}

${ }^{37}$ HEIDEGGER/FINK: Heraklit, pp. 181, 214.

${ }^{38}$ HEIDEGGER/FINK: Heraklit, p. 183.

${ }^{39}$ HEIDEGGER/FINK: Heraklit, p. 183.

${ }^{40}$ HEIDEGGER: Erläuterungen zu Hölderlins Dichtung, p. 69. 
Iniciamos a partir da questão lançada por Heidegger acerca da possibilidade de uma determinação sobre o ser ou não-ser dos deuses. Com aquilo que alcançamos até aqui, devemos tentar concluir partindo agora da seguinte questão: “por que a delimitação entre o homem e o divino?”¹ Fundamentalmente porque nessa relação repousa "o modo mais decisivo" de determinaçáo do ente no todo. ${ }^{42}$

É muito intrigante que Heidegger, em um curso do semestre de inverno ministrado entre os anos de 1934 e 1935, tenha admitido falar de um "ser-aí histórico dos deuses" (das geschichtliche Dasein der Götter). ${ }^{43}$ Tudo leva a crer que ele toma mesmo o termo de Hölderlin, como fica claro através da conferência de 1959, Hölderlins Erde und Himmel, voltada para o poema de Hölderlin que dá nome à conferência e na qual podemos encontrar o termo "ser-aí do deus" (Daseyn Gottes). ${ }^{44}$ Termo que ele irá interpretar através do "caráter essencial de presença do deus" (Die Anwesenheit des Gottes) ${ }^{45}$ ou simplesmente da "presença do deus" (Anwesen des Gottes), ${ }^{46}$ referências que usualmente são aplicadas por ele ao ser em seu manifestar-se. E mesmo antes, na conferência Hölderlin und das Wesen der Dichtung, de 1936, Heidegger também falara ainda da "presença dos deuses" (Gegenwart der Götter), ${ }^{47}$ Essa é outra referência retirada da poesia de Hölderlin, como dessa vez atesta a conferência Das Gedicht, de $1968 .^{48}$ Nessa conferência, inclusive, se reúnem os termos em uma só expressão: Anwesenheit der gegenwärtigen Götter. ${ }^{49}$ A questão é que, assim como Anwesen, Gegenwart também é um dos termos que via de regra marca o modo de dar-se do ser dos entes em geral.

\footnotetext{
${ }^{41}$ HEIDEGGER: Sein und Wahrheit, p. 94.

${ }^{42}$ HEIDEGGER: Sein und Wahrheit, p. 94.

43 HEIDEGGER: Hölderlins Hymnen “Germanien” und "Der Rhein”, p. 98. Também na Brief über den Humanismus aparece, entre aspas, o termo Dasein Gottes. Cf. HEIDEGGER: Wegmarken, p. 350; cf. tb. p. 351.

${ }^{44}$ HEIDEGGER: Erläuterungen zu Hölderlins Dichtung, p. 161; cf. tb. pp. 173, 174. O termo aparece também no verso 6 do poema Griechenland, de Hölderlin. Cf. HEIDEGGER: Erläuterungen zu Hölderlins Dichtung, p. 155.

${ }^{45}$ HEIDEGGER: Erläuterungen zu Hölderlins Dichtung, p. 166. O mesmo termo aparece também no registro da conferência Phänomenologie und Theologie. Cf. HEIDEGGER: Wegmarken, p. 78.

${ }^{46}$ HEIDEGGER: Holzwege, p. 27.

${ }^{47}$ HEIDEGGER: Erläuterungen zu Hölderlins Dichtung, pp. 40, 42.

${ }^{48}$ HEIDEGGER: Erläuterungen zu Hölderlins Dichtung, p. 184.

${ }^{49}$ HEIDEGGER: Erläuterungen zu Hölderlins Dichtung, p. 186; cf. tb. pp. 184, 185, 190, 191, 192.
} http://seer.ucp.br/seer/index.php/synesis/index 
Entendemos que, nestes momentos, Heidegger encontra-se tacitamente em conflito com os limites da constituição ontoteológica da metafísica. Conflito que se mostra de maneira ainda mais latente através do texto Nietzsches Wort "Gott ist tot", de 1943, no qual Heidegger fala de "um deus vivo" (ein lebendiger Gott) em contraposiçáo ao "Deus e aos deuses que estão mortos no sentido da questionada experiência metafísica". ${ }^{50}$ Isto é, o Deus que se fez real e efetivo enquanto valor supremo, mas que se esgotou porque "não é pensado a partir do próprio ser”. ${ }^{51}$ Todavia, este esvaziamento para Heidegger é também índice do fato de se tratar de um "deus que por si mesmo se distancia de sua presença viva [lebendigen Anwesenheit]". ${ }^{2}$ Essa colocação é fundamental para sabermos distinguir que os deuses são passíveis de certo esvaziamento de sentido porque antes a divindade traz essa possibilidade em sua essência, isto é, em sua dinâmica histórica, em seu sentido primordial e em sua constituição originária.

Mas se o mortal náo pode anular por completo o sentido da divindade e nem reduzila ao seu próprio ser, entáo como poderia ele, frente a este distanciamento, pensar um "ser dos deuses" (Seyn der Götter) ${ }^{53}$ ou "do deus" (Gottsein) ${ }^{54}$ a partir do próprio ser? Teria Heidegger em mente a necessidade de manutenção dessa possibilidade nos momentos em que também faz mençôes de maneira extremamente intrigante ao "deus do ser" (Gott des Seins), ao "ser divino" (göttlichen Seyn) e ainda ao "ser intimamente divino" (gottinnigen Seyn)?55

Em um apontamento de 1959, a partir da célebre afirmação de Nietzsche acerca da refutação do Deus moral, Heidegger afirma o seguinte: “o Deus pensado enquanto valor, seja ele o mais elevado, não é um Deus. Logo, Deus não está morto, pois sua deidade vive. Ela, inclusive, está mais próxima do pensar do que da fé" ${ }^{56}$ Dessa importante afirmaçáo parece podermos inferir que aquele Deus declarado como "morto" por Heidegger, ainda na esteira de Nietzsche, em 1943, parece não esgotar a essência da divindade, uma vez que não a atende de maneira plena. Conseqüentemente, poderíamos concluir que a modalidade do divino que se

\footnotetext{
${ }^{50}$ HEIDEGGER: Holzwege, p. 250.

${ }^{51}$ HEIDEGGER: Holzwege, p. 255.

${ }^{52}$ HEIDEGGER: Holzwege, p. 256.

${ }^{53}$ HEIDEGGER: Hölderlins Hymnen “Germanien” und "Der Rhein”, pp. 172, 185, 192, 271, 278.

${ }^{54}$ HEIDEGGER: Sein und Wahrheit, p. 94 e HEIDEGGER: Hölderlins Hymnen "Germanien” und "Der Rhein”, p. 174.

${ }^{55}$ HEIDEGGER: Hölderlins Hymnen “Germanien” und “Der Rhein”, pp. 181, 271, 278.

${ }^{56}$ HEIDEGGER: Aus der Erfahrung des Denkens, p. 154. http://seer.ucp.br/seer/index.php/synesis/index
} 
esgota é aquela efetivada através dos aspectos entitativamente metafísicos, como a moral, a causa e o fundamento; de uma tal maneira que, resguardado em sua dimensão de mistério, o divino se recolheria em uma possibilidade mais ampla, chamada de "inesgotável" por Heidegger em "Uma carta a um jovem estudante", de $1950 .{ }^{57}$

Contudo, quando se prepara para a questão do "último deus", Heidegger volta a se questionar se "o pensamento histórico do ser, a partir de sua necessidade, pode, numa interpretação própria, ser digno de questão a partir da pergunta sobre a possibilidade de que algo como o ser possa ser atribuído aos deuses sem destruir toda deidade" ${ }^{58} \mathrm{Com}$ isso podemos perceber que mesmo já em uma fase bem avançada de seu pensamento o embaraço dessa problemática relação não pôde ser simplesmente evitado e nem sequer de todo solucionado, pois ele no fundo nunca foi capaz de negar que a pergunta pelo ser provém do mesmo fundamento a partir do qual a essência dos deuses aparece em sua divindade. ${ }^{59}$ Todavia, este "fundamento" em Heidegger é abissal, posto que é nele que o ser se distingue do ente em sua totalidade, ou seja, de tudo aquilo que é. E será justamente por isso que o último deus se mostrará imprescindível para se pensar a superação da metafísica em Heidegger, por ser um elemento no qual a questáo do divino recobra sua diferença acerca do ente. Em resposta ao vínculo metafísico entre o abandono do ser e a entificação do divino, o ser se preserva na recusa do último deus, um deus que, por ser último, nunca advém como tal.

Assim, deve ficar claro que o modo como Heidegger esforça-se para compreender uma possibilidade do divino para além do horizonte metafísico está pautado pela necessidade de resistência a toda entificação. Isto significa que o próprio ser deve ser negado aos deuses para que estes possam se preservar em sua essência. Desta forma, os deuses só se dão em sua essência na medida em que se negam. Entender isso é fundamental para a compreensão do evento da morte de Deus em uma perspectiva mais profunda, isto é, como um fenômeno decorrente da própria dinâmica essencial da deidade em seu horizonte temporal. Através dessa chave de interpretação, a morte seria tão constitutiva do divino quanto o é para o Dasein

\footnotetext{
${ }^{57}$ HEIDEGGER: Vorträge und Aufsätze, p. 177.

${ }^{58}$ HEIDEGGER: Beiträge zur Philosophie, p. 437.

${ }^{59}$ Cf. HEIDEGGER: Besinnung, p. 245.
} 
enquanto ser-finito. Daí insistirmos na idéia de uma precariedade comum que pode ser entendida enquanto "carência” através da seguinte admissão:

A negação do ser aos "deuses" significa antes de tudo somente isto: o ser não está "sobre" os deuses; mas estes também não estão "sobre" o ser. Porém, bem precisam "os deuses" do ser, apelo com o qual a essência "do" ser já é pensada. "Os deuses" não carecem do ser como sua propriedade, na qual eles encontrariam um lugar. "Os deuses" carecem do ser, que não lhes pertence, para através dele pertencerem a si próprios. O ser é aquilo necessitado pelos deuses; ele é a carência deles, e a necessidade do ser designa seu modo essencial de ser, necessitado pelos deuses, mas nunca causável e condicionável. Na medida em que os deuses carecem do ser, eles se voltam para o abismo (a liberdade) e explicitam a renúncia a todo fundar e comprovar. E táo obscuro ainda deve permanecer a necessidade do ser para o pensar para que isto dê o primeiro amparo para se pensar "os deuses" como aqueles que carecem do ser. ${ }^{60}$

Como já havíamos antecipado, a questão não deve mais girar em torno simplesmente da morte de deus, mas de sua mais radical modalidade relacional com o mortal. Entendemos que é através deste horizonte de sentido que o Da do Dasein, ou seja, o "aí" do ser-aí pode abrir para a experiência do divino a partir de seu constitutivo existencial mais próprio.

Assim, o que Heidegger nega é a identidade entre Deus e ser "como essência e fundamento de Deus" ou "como predicado possível de Deus". Em compensação, para ele, "a experiência de Deus e de sua manifestação se produz na dimensão do ser". Há uma "experiência" (Erfahrung) de Deus como há uma "experiência" do pensar. E há uma "manifestação" (Offenbarkeit) de Deus. A "questão de Deus" não é a de seu ser, mas a de sua manifestação. [...] É por isso que o que está em questão não é a "existência de Deus", mas sua presença ou sua ausência. ${ }^{61}$

Essa experiência é a da precariedade justamente porque revela a impotência do pensar diante da necessidade de determinação acerca de um possível ser de deus. A assunção dessa condição nos parece ser o meio mais apropriado de situar a possibilidade admitida e legada por Heidegger quanto a "ingressar e se manter no espaço possível de um novo encontro com os deuses". ${ }^{62}$ Logo, entendemos que querer pensar a morte de Deus numa relação possível de superaçáo com a metafísica exige pensar uma divindade que não recorra ao entitativo e, conseqüentemente, se coloque em tensão com o próprio ser que também deve se recusar para

${ }^{60}$ HEIDEGGER: Beiträge zur Philosophie, p. 438.

${ }^{61}$ ANDIA: Heidegger et la question de Dieu, p. 93.

${ }^{62}$ HEIDEGGER: Hölderlins Hymnen „Germanien“ und „Der Rhein“, p. 97. http://seer.ucp.br/seer/index.php/synesis/index 
que todo o fenômeno se dê, uma vez que o ser, enquanto condição de possibilidade para tudo aquilo que é, está em toda parte sem, contudo, poder ser encontrado como tal em parte alguma. Por fim, essa tensão essencialmente constitutiva da relação entre ser, divinos e mortais se complementa através do seguinte: na medida em que o divino se torna carente de tudo aquilo que é, através dessa precariedade ele institui a possibilidade de relação com o ser-finito que só se consuma na medida em que deixa de ser.

Logo, ser lançado no mundo significa já estar em conflito com o próprio ser, uma vez que o caráter de totalidade da existência está delimitado por sua própria condição de finitude. É neste sentido que Heidegger reconhece a "luta" (Kampff) como "essência" e "origem" do ser. ${ }^{63}$ Procuramos apontar que a compreensão ontológico-existencial do divino também está circunscrita por essa condição, de tal maneira que os deuses se revelam somente na medida em que se colocam em tensão com a própria possibilidade do ser que nunca se consuma de todo como tal e, assim, sempre se recusa.

Isto quer dizer: não se trata, sobretudo, de designar de maneira exemplar determinadas esferas ônticas, mas principalmente de tornar visível os modos fundamentais do ser em sua origem a partir da essência do ser: o ser do deus, o ser do homem, o ser escravo e o ser senhor.

Além disso, não satisfaz simplesmente levar em conta estes modos fundamentais do ser de diferentes maneiras, mas somente em seu caráter originário. Isto quer dizer: a essência do ser é luta; todo ser atravessa decisão, vitória e derrota. Não se é simplesmente deus ou apenas homem, mas com o ser é tomada uma decisão litigiosa e com isso trava-se uma luta com o ser; não se é escravo porque dentre outras coisas há algo assim, mas porque este ser abriga em si uma derrocada, um fracasso, uma insuficiência, uma crueldade [...]. Disso se torna claro: a luta instala-se no ser e nele se mantém; ela constitui a essência do ser e, na verdade, de tal forma que ela perpassa todo ente com o caráter de decisão. ${ }^{64}$

O que tentamos evidenciar aqui é que, a partir do modo como Heidegger compreende a dinâmica essencial do divino, os deuses, assim como o Dasein, ainda que de uma maneira própria, também se desdobram "constantemente ao longo dessa margem do não. Isso significa: no ser-colocado-diante-de-si-próprio em vista de suas possibilidades próprias também

${ }^{63}$ HEIDEGGER: Sein und Wahrheit, p. 94.

${ }^{64}$ HEIDEGGER: Sein und Wahrheit, pp. 94-95. 
se mostra sempre o poder-não-ser" ${ }^{65}$ Neste sentido, entendemos que "esse caráter de não", tão próprio ao Dasein, também pertence à essência dos deuses, de uma forma que se torna indispensável para a compreensão do horizonte de transcendência do próprio ser-no-mundo.

É justamente em virtude do fato de divinos e mortais reportarem ao abismo do ser a partir de recusas de si que lhes são próprias que Heidegger entende que a essência da história provém da tensão entre homens e deuses. ${ }^{66}$ Entendemos que essa tensão apresenta de maneira dramática, isto é, em uma relação de resistência e, ao mesmo tempo, de proximidade com a metafísica, um colocar-se em jogo da própria essência do ser em sua totalidade. Colocar-se em jogo significa aqui assumir o próprio risco de ser, pois é através dessa tensa relação com os mortais que os deuses também têm de se confrontar com o risco da perda do ser. Risco que náo os anula, mas antes os constitui, posto que é justamente por meio deste jogo que os deuses, "na verdade continuam perdurando, como ausentes, depois que morreram". ${ }^{67}$ Mas diante de nossa impossibilidade de determinar um sentido último para esse jogo entre presença e ausência, o que nos cabe aqui apontar de maneira conclusiva é que, em se tratando de um jogo, ele é mútuo, isto é, diz respeito tanto aos mortais quanto ao divino.

${ }^{65}$ HEIDEGGER: Einleitung in die Philosophie, p. 332.

${ }^{66}$ Cf. HEIDEGGER: Hölderlins Hymne “Andenken”, p. 77. O que faz também com que a Ereignis, uma das mais importantes noções de seu pensamento, responda pelo mesmo conflito. Cf. HEIDEGGER: Hölderlins Hymne “Andenken", p. 77.

${ }^{67}$ NUNES: Crivo de papel, p. 38. 


\section{Referências bibliográficas}

ANDIA, Ysabel. Heidegger et la question de Dieu. In: Revue Thomiste. Revue Doctrinale de Théologie et de Philosophie, Paris, XCa année, tome CXXXII, No 1, pp. 90-99, jan./mar. 1982.

BRITO, Emilio. Heidegger et l'hymne du sacré. Louvain: Presses Universitaires, 1999.

Les dieux et le divin d'après Heidegger. In: Ephemerides Theologicae Louvanienses,

Louvain: Université Catholique de Louvain, pp. 53-91, abril 1999.

DUBOIS, Christian. Heidegger: introdução a uma leitura. Trad. Bernardo Barros Coelho de

Oliveira. Rio de Janeiro: Zahar, 2004.

HEIDEGGER, Martin. Aus der Erfahrung des Denkens. 2. Aufl. Frankfurt am Main: Vittorio

Klostermann, 2002 [1983] (Gesamtausgabe: Bd. 13).

Beiträge zur Philosophie (Vom Ereignis). 3. Aufl. Frankfurt am Main: Vittorio

Klostermann, 2003 [1989] (Gesamtausgabe: Bd. 65).

Besinnung. Frankfurt am Main: Vittorio Klostermann, 1997 (Gesamtausgabe:

Bd. 66).

Die Grundbegriffe der Metaphysik. Welt - Endlichkeit - Einsamkeit. 3. Aufl.

Frankfurt am Main: Vittorio Klostermann, 2004 [1983] (Gesamtausgabe: Bd. 29/30).

Einführung in die Metaphysik. 6. Aufl. Tübingen: Max Niemeyer, 1998 [1953].

Einleitung in die Philosophie. 2. Aufl. Frankfurt am Main: Vittorio Klostermann,

2001 [1996] (Gesamtausgabe: Bd. 27).

Erläuterungen zu Hölderlins Dichtung. 6. Aufl. Frankfurt am Main: Vittorio

Klostermann, 1996 [1944].

Hölderlins Hymnen "Germanien” und "Der Rhein”. 3. Aufl. Frankfurt am Main:

Vittorio Klostermann, 1999 [1980] (Gesamtausgabe: Bd. 39).

Hölderlins Hymne "Andenken”. 2. Aufl. Frankfurt am Main: Vittorio Klostermann,

1992 [1982] (Gesamtausgabe: Bd. 52).

Holzwege. 6. Aufl. Frankfurt am Main: Vittorio Klostermann, 1980 [1950]. 
Metaphysik und Nihilismus. 1. Die Überwindung der Metaphysik. 2. Das Wesen des Nihilismus. Frankfurt am Main: Vittorio Klostermann, 1999 (Gesamtausgabe: Bd. 67). Sein und Wahrheit. 1. Die Grundfrage der Philosophie. 2. Vom Wesen der Wahrheit. Frankfurt am Main: Vittorio Klostermann, 2001 (Gesamtausgabe: Bd. $36 / 37)$.

Über den Anfang. Frankfurt am Main: Vittorio Klostermann, 2005 (Gesamtausgabe: Bd. 70).

Vorträge und Aufsätze. 10. Aufl. Stuttgart: Klett-Cotta, 2004 [1954].

Wegmarken. 3. Aufl. Frankfurt am Main: Vittorio Klostermann, 2004 [1976]

(Gesamtausgabe: Bd. 9).

HEIDEGGER, Martin; FINK, Eugen. Heraklit. 2. Aufl. Frankfurt am Main: Vittorio Klostermann, 1996 [1970].

NUNES, Benedito. Crivo de papel. São Paulo: Ática, 1998.

STEIN, Ernildo. Compreensão e Finitude. Estrutura e movimento da interrogação heideggeriana. Ijuí: Unijuí, 2001. 